\title{
Translations and turkey
}

\section{New York City}

TWENTY-THREE editors of Soviet physics journals assembled in New York last week under the auspices of the American Institute of Physics (AIP) to meet their US counterparts and discuss the translation of Russian-language journals into English and vice versa. At the end of the meeting, over a traditional US Thanksgiving Day meal of turkey, dressing and cranberry sauce, the participants agreed that the contacts they made would serve them well in bringing the two communities closer together, and, in particular, that the US scientists were given valuable insight into the problems now facing Soviet science.

The AIP has contracts to translate 20 of the best Soviet physics journals into English, including Doklady and the Journal of Experimental and Theoretical Physics. Recently, the institute has begun to publish some of its translations simultaneously with the release of the Russian-language journals by obtaining the contents of the journals before they are published. Indeed, Valerii Ozhogin, editor of Superconductivity, said he received the English translation of the most recent issue of his journal before he got the Russian version. This has given him ammunition, he said, to prod the publisher of the journal to speed up its publication.
Although the US representatives reported some complaints and concerns about the quality of the translations, the Soviets for the most part seemed satisfied with that part of the arrangement. They did not, however, seem ready to make any guarantee that the AIP would remain the exclusive translator of the physics journals. That translation is a lucrative business, and some of the Soviet editors seemed to sense that they might get a better deal by opening up the bidding.

The most sensitive issue was whether the Soviet journals would remain Russian-language publications or would change to English, as have the top scientific journals in continental Europe and Japan. The consensus among the Soviets seemed to be that with successful simultaneous publication of English- and Russian-language versions of the journals, there is little reason to switch to English, and that there are good reasons not to.

Many Russian scientists do not read or write English well, Ozhogin said, and they would be seriously handicapped if the best Soviet papers were published in English. Few English-language journals are translated into Russian editions, however, so Soviet scientists must find some way to get around the language barrier. Apparently the scientists whose specialties make

\section{Little accord on priorities}

\section{Washington}

THE US government is apparently becoming more serious about investigating the claims that low-frequency electromagnetic fields (EMFs) may affect human health. Last week, officials from the Department of Energy (DOE) assembled EMF experts from universities, electric utilities, and state and federal agencies to begin developing a coordinated federal programme to study possible connections between EMF exposure and increased risks of cancer and other health problems.

In the 1992 appropriations bill that set the DOE budget, Congress stated that it supports "continued research on the potential health effects of electromagnetic fields" and asked "that the Department of Energy be the lead agency for such research and that research conducted by the government be coordinated through the Department." Congress did not, however, increase its funding for EMF research in fiscal year 1992 - the DOE's portion, for instance, stayed approximately constant at $\$ 5$ million.

The energy department moved quickly to begin coordinating EMF studies, which are supported not only by DOE but also by a variety of federal and state agencies and utilities. In the past, what little coordination that existed among these programmes has been informal and sporadic.

The organizers of the DOE workshop had hoped to set some priorities on EMF research, but with the wide range of researchers represented, every approach to studying the problem had its defenders. Everyone agreed, for instance, that it is essential to develop some idea of what 'dose' means when speaking of exposure to EMFs - most research indicates that it is not enough to measure simply the magnitude and duration of the applied field, but factors such as frequency, orientation, peak field and pulsing may also be important. However, some participants argued from this for more laboratory work, while others urged better epidemiological studies. The upshot was that no clear priorities were evident at the end of the meeting that were not already generally accepted at the beginning.

Nonetheless, DOE intends to keep to an ambitious schedule for establishing its unified EMF strategy. It plans to develop the strategy over the next month, hold public meetings to discuss it in January and February, and begin to implement the plan in the spring. it essential for them to read English-language journals do learn to read English, but the majority of Soviet scientists are still uncomfortable with the language.

The Soviets acknowledged that more and more of their best researchers are getting jobs in the West, particularly with the mounting economic problems in the Soviet Union. This, combined with the general opening up of the country has led to more Soviet scientists publishing their papers in English, and this puts pressure on the Russian-language publications. Superconductivity accepts manuscripts in English and translates them for publication, for instance, but even so there are worries that English-language publications will skim off the cream of Soviet science, leaving the Russian-language publications with the lesser papers.

One fact came out at the meeting that illustrated how difficult it is for Soviet scientists to move around and communicate with their peers. Most of the Soviet editors were meeting each other for the first time - they had to travel to the United States to meet colleagues who live in different cities in the Soviet Union.

Another discovery was that the Soviets are just as confused about what to call their country as the Americans. One US speaker stopped in mid-sentence to ask, "Is it the Soviet Union or Russia?" The response from one visiting scientist: "We don't know either."

Robert Pool

\section{UNDERWATER EXPLORATION}

\section{Jason lost at sea}

JASON Jr., the robotic underwater explorer that first explored the Titanic, was lost last week when the barge carrying it to the Galapagos islands foundered and sank in 9,000 feet of water off Ecuador. No lives were lost, but the submarine and several containers of video and electronic equipment are considered unsalvageable. Most of the \$20 million loss was insured, says Woods Hole Oceanographic Institution spokeswoman Shelly Lauzon.

Early this week, Jason officials said they were "optimistic" that the project which is to provide a glimpse of a live scientific expedition to 500,000 students in North America - will be able to begin on 2 December as planned. Woods Hole and the Massachusetts-based Jason Foundation for Education have located three available submersibles and replacements for much of the electronic equipment. They hope to airlift the supplies to the Galapagos by mid-week. The replacement submersibles, known as mini-rovers, are designed for commercial uses in much shallower water than Jason Jr., which can descend to depths of several thousand feet. But because the project is only designed to explore the islands at depths of a few hundred feet, team members hope to be able to stick to their original plans. C.A. 